УДК $81 ' 42(075.8)$

DOI 10.52575/2712-7451-2021-40-4-442-450

\title{
Мультимодальность медиатекста в новом коммуникативном пространстве (наблюдения и замечания)
}

\author{
Пстыга А. \\ Гданьский университет, \\ Польша, г. Гданьск, 80-308, ул. Wita Stwosza, 51 \\ e-mail: alicja.pstyga@ug.edu.pl
}

\begin{abstract}
Аннотация. Рассмотрены вопросы дискурсивной деятельности СМИ, связанные с кодированием, декодированием и перекодированием медиатекста. В центре внимания мультимодальность как фактор, который активно используется в формировании текстовой действительности и предопределяет вектор интерпретации текста, а в другом коммуникативном пространстве (в переводческой перспективе) меняется соответственно установке редакции журнала и/или переводчика. Таким образом, необходимой становится новая методологическая перспектива анализа мультимодального медиатекста. С этой точки зрения сам выбор текста для перевода оказывается значимым, поскольку он неразрывно связан с избирательностью и оценкой информации. Данный подход требует глобального рассмотрения соотношений в межтекстовом пространстве, учитывающих мультимодальные элементы структуры медиатекста, которые оказывают влияние на аксиологическое измерение всего сообщения, что одновременно позволяет выявить степень симметрии между оригиналом и переводом.
\end{abstract}

Ключевые слова: медиатекст, мультимодальность, коммуникация, перевод

Для цитирования: Пстыга А. 2021. Мультимодальность медиатекста в новом коммуникативном пространстве (наблюдения и замечания). Вопросы журналистики, педагогики, языкознания, 40 (4): 442-450. DOI: 10.52575/2712-7451-2021-40-4-442-450

\section{Multimodality of Media Text in New Communication Space (Observations and Comments)}

\author{
Alicja Pstyga \\ University of Gdańsk, \\ 51 Wita Stwosza St, Gdańsk 80-308, Russian Federation \\ e-mail: alicja.pstyga@ug.edu.pl
}

\begin{abstract}
In the article the author discusses some aspects of discursive activity of media connected to coding, decoding and transcoding of the media text. Emphasis is placed on the multimodality, which is actively used in shaping of the reality of the text and predetermines the direction of its understanding. In different communicative space (after translation) it can be changed accordingly to magazine's or translator's intention. Then, methodological problems are enumerated. From this point of view, the selection of the text for translation appears to be significant as it is related to the selection and evaluation of information. Such an approach requires a holistic analysis of intertextual relations, also including other elements of the text structure (in terms of multimodality) which affect axiological aspects of the entire message, identifying the degree of symmetry between the oryginal text and its translation.
\end{abstract}

Keywords: media text, multimodality, communication, translation

For citation: Pstyga A. 2021. Multimodality of Media Text in New Communication Space (Observations and Comments). Issues in Journalism, Education, Linguistics, 40 (4): 442-450 (in Russian). DOI: $10.52575 / 2712-7451-2021-40-4-442-450$ 


\section{Медиатекст: между логоцентризмом и методологической интеграцией}

Мультимодальность, медиаконвергентность и рецептивный подход считаются ведущими параметрами в современном изучении медиатекста. Медиатекст, который исследователи [Добросклонская, 2008; Żydek-Bednarczuk, 2013; Казак, 2014; Полонский, 2015; Maćkiewicz, 2016; Piekot, 2006; Skowronek, 2016; Loewe, 2018] определяют как многоаспектное, многоуровневое явление, основанное на единстве языковых и медийных признаков, как продукт разных форм массовой коммуникации (журналистики, рекламы и связей с общественностью), рассчитанный на массовую аудиторию, и одновременно как единицу языка СМИ, требует интерпретации, опирающейся на разные медийные структуры, сопровождающие вербально изложенные смыслы и участвующие в глобальной семантике текста. В дискурсивной деятельности СМИ данные факторы (с доминируюшей ролью поликодовости и ее эстетического потенциала) обогащают традиционный логоцентрический подход к анализу текста и выявляют разные аспекты соформирования медийной текстовой действительности, специфику его функционирования в определенном медиапространстве, его понимания и восприятия, что обозначает интердисциплинарный характер исследований и применение неоднородных исследовательских процедур. Таким образом анализ включает, кроме лингвистического, социологический аспект, культурно-социальный контекст, точку зрения адресанта и адресата, ситуативный контекст и установку на интеракции, а также роль невербальных семиотических средств. Все перечисленные вопросы можно рассматривать также в рамках медиакритики [Кожемякин, 2010; Короченский, 2018a; 2018б; Полонский, 2018; Кожемякин, 2019; Pstyga, 2021a; 2021b].

В свою очередь, содержащаяся в заглавии статьи формулировка в новом коммуникативном пространстве предусматривает исследование вопросов анализа медиатекста в сопоставительном плане - как последовательность действий в межтекстовом пространстве между оригиналом и переводом, которые оцениваются с точки зрения влияния на восприятие медийного содержания реципиентом, в частности реципиентом переведенного медийного коммуниканта, функционирующего в новой для него коммуникативной среде. Данная установка позволяет расширить исследовательскую перспективу и дополнить те вопросы, которые были затронуты в статье «Медиатекст и перевод» [Пстыга, 2019].

Итак, напомним, что международные (одновременно межъязыковые и межкультурные) аспекты медийного коммуникативного пространства включают трансляцию информации о современном мире, в том числе и постановку информации о чужой действительности, мнении и оценках, а также о событиях, протекающих в стране, в которой перевод появляется, которые перекрещиваются с проблемой формирования медийной действительности и ее интерпретации с точки зрения получателя, принадлежащего к определенной коммуникативной среде. В переводоведческом аспекте данная проблема ставится редко, так как, как полагается, перевод воспроизводит действительность оригинала, то есть сводится к конструированию его текстовой репрезентации. Однако на основе анализа контента и сопоставления этих двух текстов (в рамках критики перевода и медиакритики) наблюдаются некоторые расхождения, позволяющие в новом коммуникативном пространстве отметить случаи влияния на медийную действительность текста перевода. Следует подчеркнуть, что в рамках воссоздания (или соформирования?) текстового пространства, учитывая все особенности перевода медийного текста [Pstyga, 2021b], в процессе включения медиатекста в новое коммуникативное пространство происходит смена точки зрения, перспективы и системы ценностей, меняется и социокультурный контекст, в котором переведенный текст функционирует, выполняя уже другую функцию [Lewicki, 2017] и сохраняя некоторую автономность. Смена кода (перекодирование) и возможная модификация медиатекста в процессе перевода, чаще всего его сокращение с селективностью отбора информации, дополнение новой информацией согласно установке на другого читателя и его знания, требование компрессии текста и добавление графики, соотносится с функцией каждого переведенного текста, поскольку представленная в нем информация имеет уже другое значение для другого потребителя, который получает данную информацию позже, чем читатель оригинала, и 
знакомится с ней с совершенно иной целью, а сам текст должен одновременно привлекать его внимание, являясь формой инфотейнмента, игры, развлечения [Пстыга, 2019; Pstyga, 2021b]. Поэтому есть основания для того, чтобы ввести фактор интенциональности в сферу модификаций содержания и оформления статьи в переводческом варианте, для чего используется также мультимодальность. На этом фоне обоснованным представляется нам вопрос о роли всех составляющих в пределах единого коммуниканта в конечной интерпретации текста (оригинала или/и перевода) представителем определенной языковой общности в конкретном коммуникативном пространстве.

\section{Мультимодальность и различные коммуникативные пространства}

Мультимодальность (поликодовость) можно считать в этом плане наиболее эффективным и значимым фактором, в глобальной интерпретации медиатекста и его воздействии на получателя играющим важную роль [Maćkiewicz, 2016; Кожемякин, 2019; Lisowska-Magdziarz, 2019; Pstyga, 2021a] и во многом предопределяющим интерпретацию сообщения. Именно поликодовые средства своей невербальной природой привлекают внимание читателя, вносят дополнительный компонент оценочности сообщения и усиливают ценностные ориентиры текста. Таким образом, с точки зрения функционирования медиатекста в новом коммуникативном пространстве - посредством перевода - следует подчеркнуть значимость не только отбора тематики (информации) и текста для перевода [Piekot, 2006; Stőckl, 2015], но также роль его оформления, что привлекает внимание исследователя и реципиента как на уровне отбора языковых структур, так и визуального кода, учитывая заголовочный комплекс, шрифт, сопровождающие вербальную информацию фотографии и подпись к ним, схемы и рисунки.

Используя русскоязычные медиатексты (из печатных источников, их цифровых версий и интернет-сайтов) и их последующий перевод на польский язык в журнале Forum (печатной и цифровой версиях), предлагаем рассмотреть специфику мультимодального мультимедийного текста и роль различных кодов в передаче глобального смысла оригинала с точки зрения меняющейся коммуникативной среды и восприятия другим, соответственно коммуникативному пространству, читателем. Рассматртивая мультумодальность как фактор, участвующий в создании смысла коммуниканта и предопределяющий его воздействие и интерпретацию, сосредоточиваем внимание на различных возможностях оформления текста в новом коммуникативном пространстве - от воспроизведения (как правило, частичного) к созданию совершенно нового.

Сопоставляя тексты, следует отметить, что лейаут устанавливается редакцией журнала, заголовочный комплекс, как правило, создается заново - соответственно требованиям журнала, а графическое оформление в силу действия определенных законов (авторские права), но также решения или желания редколлегии, предлагаются в новой форме.

Case study. Как пример нами отобраны два текста, которые относятся к разным жанрам, содержание которых в переводе воспроизводится полностью (учитывая, что качественный перевод не является буквальным) и которые объединяет интересное оформление, отличающееся от оригинала: репортаж (рис. 1,2$)$ и аналитическая статья (рис. 3,4$)$, обращая внимание на фрагменты, непосредственно соотносящиеся с использованием визуального кода.

Репортаж «Стационар для пернатых» (см. рис. 1) представляет деятельность центра спасения диких животных в случае экологической катастрофы. Заголовочный комплекс непосредственно вводит в содержание (см. лид: Единственный в России иентр реабилитации диких животных, созданный на Сахалине, имеет уникальную специализацию здесь готовят персонал $\kappa$ спасению особой категории "пачиентов" - загрязненньх нефтью диких животных.), а фотографии и подписи к ним являются иллюстрацией и документом работы специалистов (ср. Птииу надо умело поймать и самое главное - не травмировать; Геннадий Добренко и утка демонстрируют, как надо лечить пострадавших птии). 


\section{Стационар для пернатых}

Единственный в России центр реабилитации диких животных, созданный на Сахалине, имеет уникальную специализацию - здесь готовят персонал к спасению особой категории "пациентов" — загрязненных нефтью диких животных

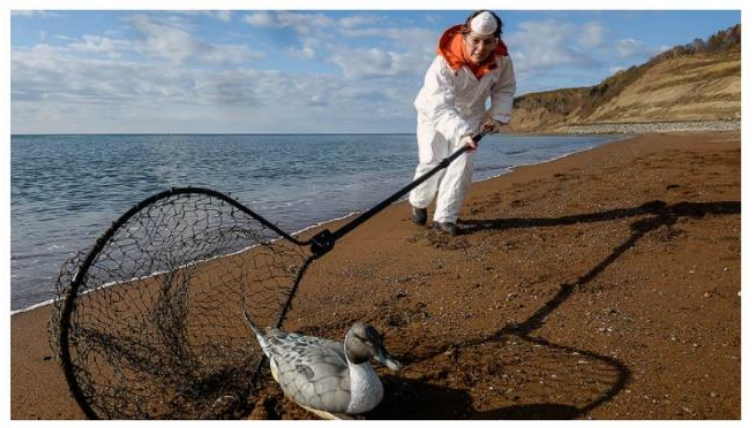

Птицу надо умело поймать и самое гпавное - не травмировать
Фото: Эмин Дикафаров, Конмерсанть

Андраник Агафонов

Сахалин. Берег Охотского моря. Песчаный пляж пестрит людьми в белоснежныхи оранжевых защитных комбинезонах. Вдоль кромки воды тянется гирлянда ярко-желтых надувных шаров с черными пятнами, а мерный шелест волн прерывается звуком сирены. Так выглядит полевой тренинг специалистов единственного в России центра по
Гонка со временем

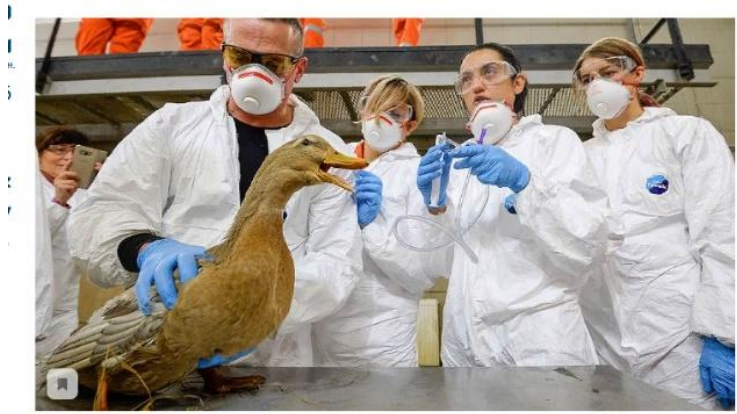

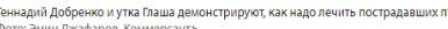

Нынешний тренинг, впрочем, особенный: он проводится среди представителей пяти нефтедобывающих компаний, органов власти и общественных организаций. Это позволит обменяться опытом, выработать навыки оперативного взаимодействия, найти решение сложных правовых аспектов деятельности в чрезвычайных ситуациях. Одна из дискуссионных тем - спасение краснокнижных видов. Существующие нормативы, объясняют специалисты, часто противоречат друг другу. Кпримеру, российское законодательство разрешает изьятие краснокнижного животного из природных условий в случае угрозы жизни, однако надзорные органы не всегда прислушиваются к доводам спасателей. В итоге забота о редких видах может обернуться претензиями и штрафами.

Ключевой параметр эффективности работы по спасению загрязненных нефтью диких

Рис. 1. Фрагменты репортажа Андраника Агафонова «Стационар для пернатых» (https://www.kommersant.ru/doc/3447646)

Fig. 2. Fragments of the report by Andranik Agafonov "Hospital for birds" (https://www.kommersant.ru/doc/3447646)

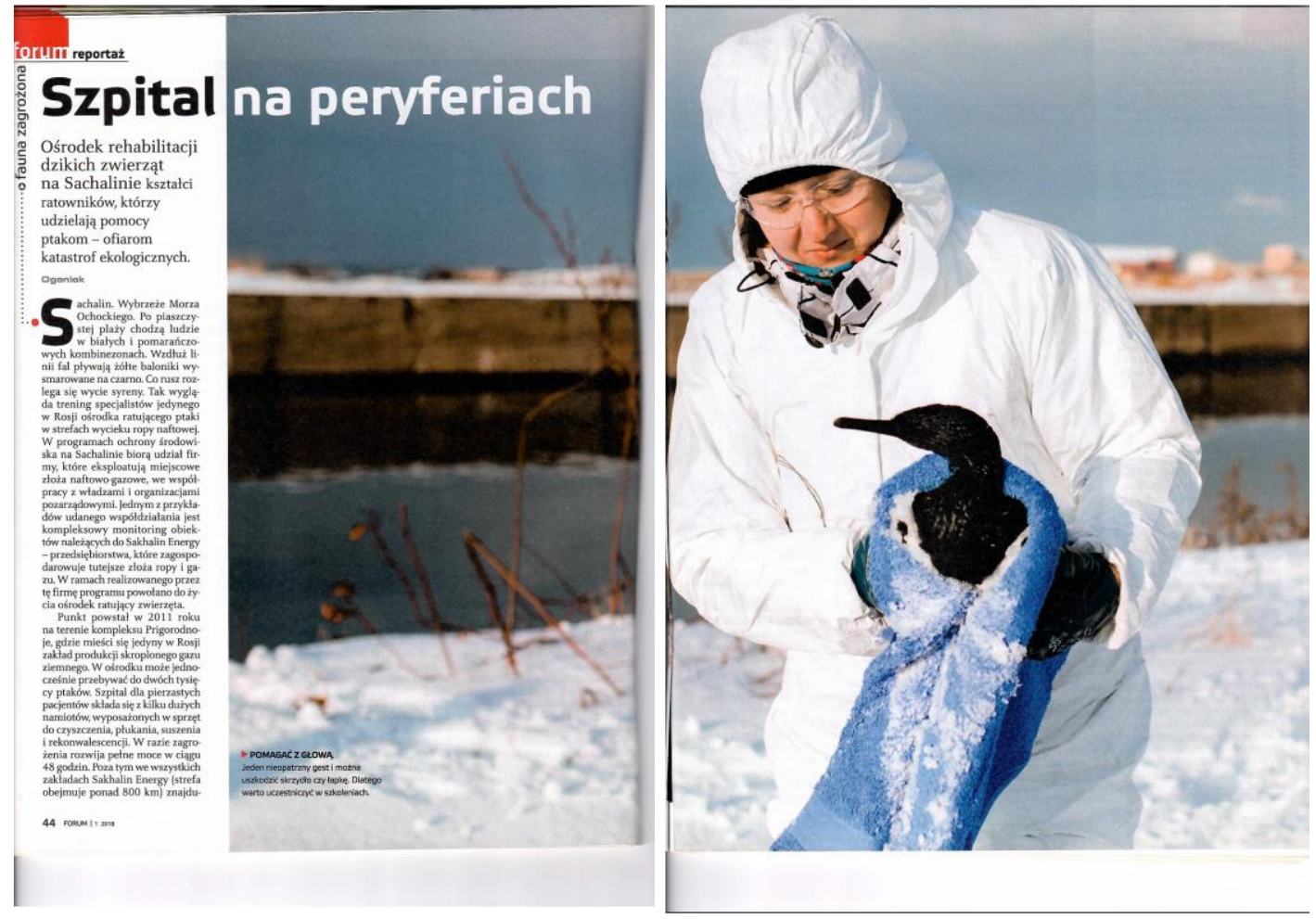

Рис. 2. Перевод русскоязычной статьи на польский язык, опубликованный в журнале Forum (Forum, 2018, № 1, c. 44-45).

Fig. 2. Media Text Translated from Russian into Polish, published in the magazine «Forum» (Forum, 2018, No. 1, pp. 44-45). 
В польскоязычной версии (см. рис. 2) своим заглавием Szpital na peryferiach статья соотносится - как использование интертекстуальности, интерсемиотичности - с названием чешского сериала под таким же заглавием о больнице на окраине города, ее врачах и их пациентах. Как проявление языковой игры, в рамках которой заголовок может получать двойную интерпретацию, т.е. либо соотносится с заглавием фильма (комедии), либо можно его рассматривать буквально, что не помешает интерпретации, тем более что фотографии, иллюстрирующие содержание, в любой ситуации своей выразительностью привлекают внимание читателя, являясь приятным фоном для повествования. В переведенном тексте в рубрике «репортаж» они не повторяют того, что предложено в оригинале, но хорошо подобраны, им отведено достаточно большое пространство и они полностью соотносятся с содержанием статьи. Подпись к приведенной выше фотографии (Pomagać z głowa. Jeden nieopatrzny gest i można uszkodzić skrzydto czy tapkę. Dlatego warto uczestniczyć w szkoleniach.) повторяет фрагмент текста.

В подлиннике фотографий больше, и они являются своеобразным документом.

Второй пример - статья Ивана Преображенского - касается президентских выборов в Польше, в которых победил Анджей Дуда (рис. 3, 4).

\section{Поляки оставили президентом Дуду из страха перед будущим}

После воскресной мессы обыватели массово проголосовали за кандидата, сумевшего свести свою кампанию к обсуждению «традиционных ценностей».

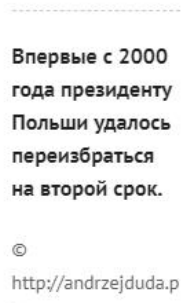

http://andrzejduda.p

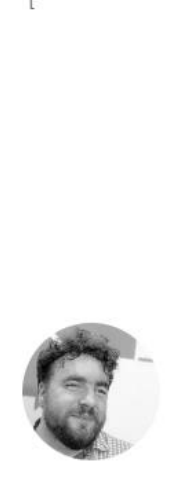

Иван

Преображенский

Политолог,

обозреватель

ИА «Росбалт»

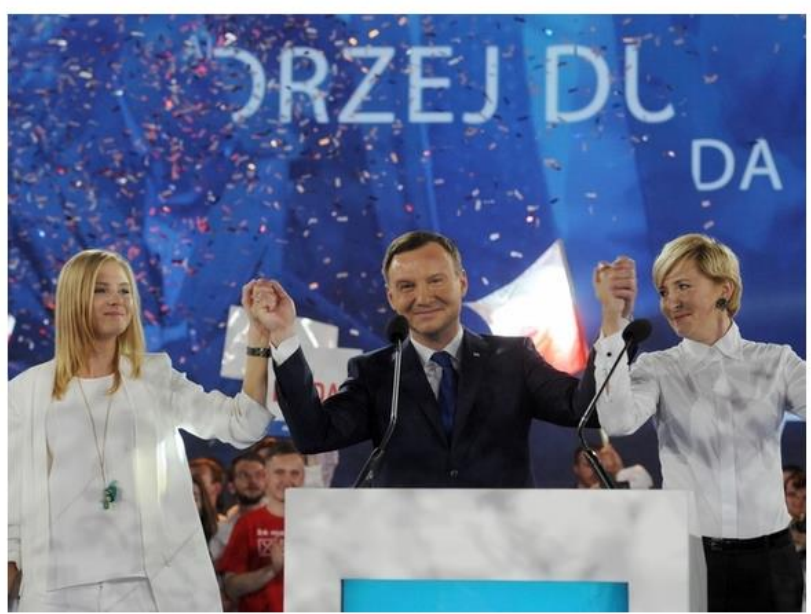

Действующий президент Польши консерватор Анджей Дуда победил на выборах с отрывом в 450 тысяч голосов - это всего 2,5 процента от числа пришедших на участки. «Мобилизация костела» оказалась в Польше сильнее гражданской солидарности. В итоге впервые с 2000 года польскому президенту удалось переизбраться на второй пятилетний срок.

Рекордную для Польши явку почти в 70\% избирателей сделали не обитатели крупных городов, хотя и их пришло к избирательным урнам заметно больше, чем в последние годы, а провинциальные, деревенские жители. Польским либералам впору добиваться к предстоящим в 2023

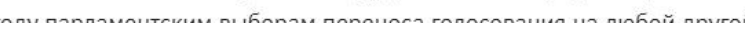

Рис. 3. Фрагмент статьи Ивана Преображенского «Поляки оставили президентом Дуду из страха перед будущим» (https://www.rosbalt.ru/blogs/2020/07/13/1853485.html)

Fig. 3. Fragment of the article by Ivan Preobrazhensky "Poles left Duda as president out of fear of the future" (https://www.rosbalt.ru/blogs/2020/07/13/1853485.html) 


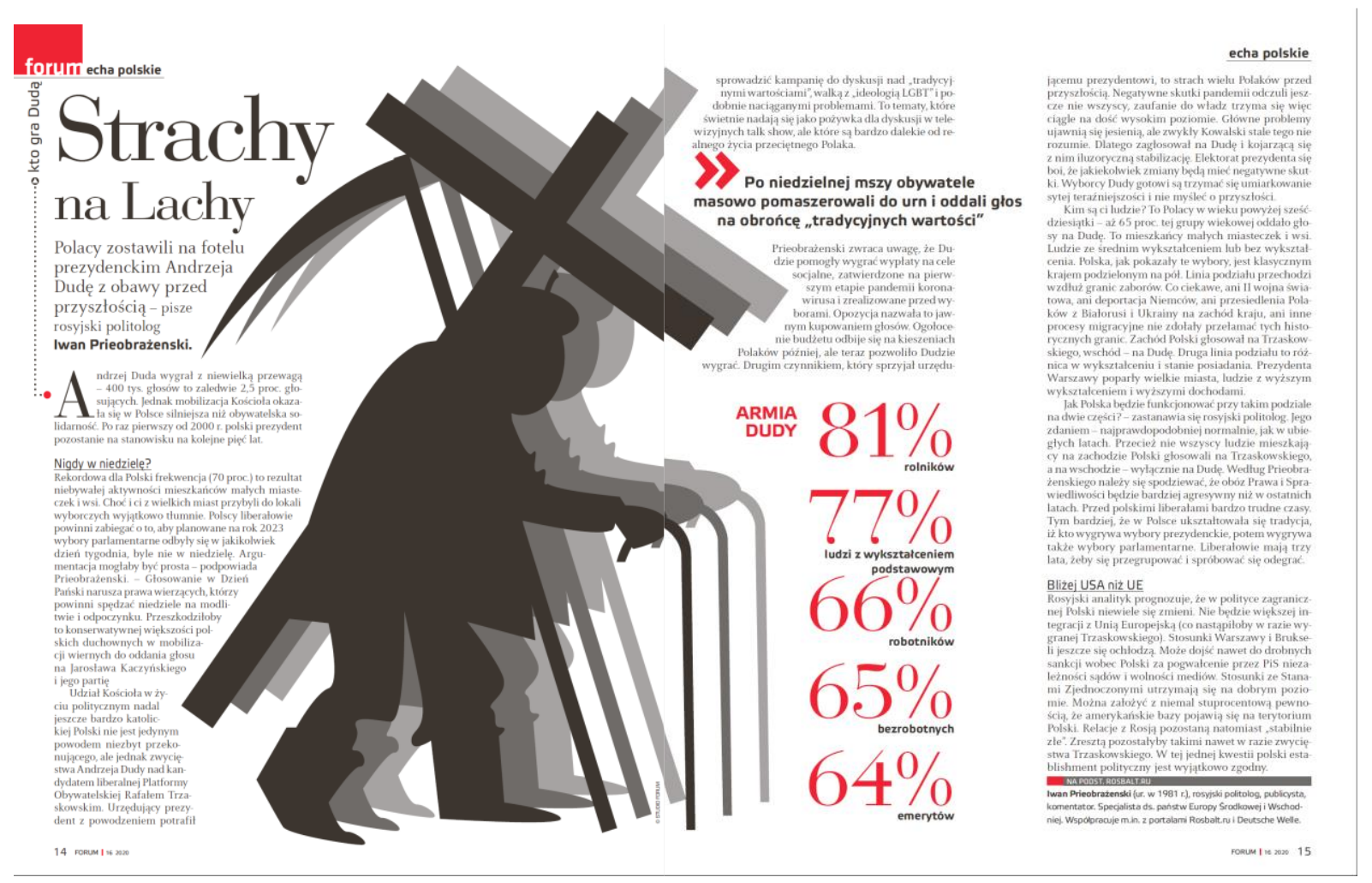

Рис. 4. Перевод русскоязычной статьи на польский язык, опубликованный в журнале Forum (Forum, 2020, № 16, c. 14-15)

Fig. 4. Media Text Translated from Russian into Polish, published in the magazine «Forum» (Forum, 2020, No. 16, pp. 14-15)

Российский политолог в своем тексте комментирует это событие, указывает на причины такой ситуации и раскрывает структуру и специфику электората А. Дуды. В польскоязчной версии меняется заглавие - это известная фразема Strachy na Lachy ('нечего бояться'), которая в данном случае привлекает внимание, отличаясь также персуазивностью. Заглавие оригинала дается как лид (ср: Polacy zostawili na fotelu prezydenckim Andrzeja Dudę z obawy przed przyszłościa - pisze rosyjski politolog Iwan Prieobrażenski.). Meняется и графическое оформление, которое, вместе с лейаутом и дополнительным текстом kto gra Duda (кто играет Дудой), является выразительным, воздействующим, оценочным элементом коммуниканта. Графика, заменяющая фотографию счастливого президента с дочерью и женой, представляет его избирателей - пожилых, необразованных людей с атрибутами, связанными с деревней и костелом, которая вместе с подписью Armia Dudy (Армия Дуды) и статистикой (красным цветом) оказывает сильное влияние на польского читателя. Добавим, что очередная фотография, представленная в оригинале, изображает президента РФ, а подпись к ней можно считать своеобразным комментарием к российскопольским отношениям, однако это интерактивный элемент - анонс, позволяющий открыть очередную статью, в которой речь идет о соседях РФ.

Проанализированный материал (в том числе и указанные выше примеры) позволяют поставить и другой вопрос: как оценить (и как измерить) не столько качество перевода, принимая установку, что надо различать собственно перевод - в полной версии и перевод «на основе», для которого исходный текст является лишь основой (что тщательно отмечается в журнале «Forum»), а коммуникативную ценность переведенного текста в принимающей его новой медийной среде. Модификация графического оформления или его изменение влияет на привлекательность текста, что небезразлично с точки зрения отбора материала журнала для чтения, а также интерпретации в целом. Поэтому важно оценить и 
определить, которой медийной действительности подчиняется данный (вторичный) медиатекст, функционирующий в новом медйном пространстве, в новом контексте, на другом языке, с учетом предпочтений другого читателя, одновременно обращая внимание на функцию переведенного текста [Пстыга, 2019, с. 195], которая, как показывают наблюдения, не всегда совпадает с функцией текста оригинала.

\section{Выводы}

Наблюдения позволяют констатировать, что заголовочный комплекс в тексте перевода полностью подчиняется привлекательности и открывает персуазивную силу и воздействие на реципиента - представителя определенного коммуникативного пространства и вместе с новыми элементами визуального кода (фотографией, графикой) дополняет и подсказывает вектор интерпретации текста. Таким образом, все составляющие компоненты единого текстового пространства могут использоваться для ценностной интерпретации текста и воздействия текста на реципиента.

Визуальный код, как визитная карточка, «приглашает» читателя, привлекает его внимание своей эстетикой и вместе с заголовочной частью влияет на привлекательность медийного коммуниканта, предопределяя возможную (предусмотренную) интерпретацию. Данный подход ведет к тому, что переведенный медиатекст в новом коммуникативном пространстве, в новом для него принимающем контексте, отличается использованием мультимодальных средств.

Мультимодальная перспектива в оценке медийных двутекстов, как показывает материал, переносит акцент на рецепцию и доказывает, что возможности и компетенции реципиента необходимы для анализа и синтеза всего медийного коммуниканта, что интерпретация требует от получателя раскрытия тонкостей всех составляющих его компонентов.

\section{Список литературы}

1. Добросклонская Т.Г. 2008. Медиалингвистика: системный подход к изучению языка СМИ: современная английская медиаречь. Москва, Флинта, Наука, 264 с.

2. Казак М.Ю. 2014. Современные медиатексты: проблемы идентификации, делимитации, типологии. Медиалингвистика, 1(4). URL: https://medialing.ru/sovremennyemediateksty-problemy-identifikacii-delimitacii-tipologii/ (дата обращения: 1.09.2021).

3. Кожемякин Е.А. 2010. Массовая коммуникация и медиадискурс: к методологии исследования. Научные ведомости Белгородского государственного университета. Серия: Гуманитарные науки, 12 (83): 13-21.

4. Кожемякин Е.А. 2019. Медиатекст в мультимодальной перспективе: несколько метдологических замечаний. В кн.: Дискурсология и медиакритика современных средств массовой информации. Сборник трудов международной научно-практической конференции, 2-4 октября 2019 , г. Белгород. Под ред. А.В. Полонского, С.В. Ушаковой, С.М. Нарожняя. Белгород, ИПЦ «ПОЛИТЕРРА»: 158-164. URL: https://journ.bsu.edu.ru/files/discourse2019.pdf (дата обращения: 1.09.2021).

5. Короченский А.П. 2018а. Тенденция гибридизации медиатекстов как этический вызов журналистике. В кн.: Медийный текст: социальные практики, технологии, теории. Под ред. А.В. Полонского, М.Ю. Казак. Белгород, ИД «Белгород» НИУ «БелГУ»: 147-150.

6. Короченский А.П. 2018б. Медиакритика как дискурс. В кн.: Медийный текст: социальные практики, технологии, теории. Под ред. А.В. Полонского, М.Ю. Казак. Белгород, ИД «Белгород» НИУ «БелГУ»: 218-219.

7. Полонский А.В. 2015. Медиа и их текстовая реальность. Научные ведомости Белгородского государственного университета. Серия: Гуманитарные науки, 18 (215): 17-24.

8. Полонский А.В. 2018. Медийный текст и его статус в современной культуре. В кн.: Медийный текст: социальные практики, технологии, теории. Под ред. А.В. Полонского, М.Ю. Казак. Белгород, ИД «Белгород» НИУ «БелГУ»: 9-24.

9. Пстыга А. 2019. Медиатекст и перевод. В кн.: Дискурсология и медиакритика современных средств массовой информации. Сборник трудов международной научнопрактической конференции, 2-4 октября 2019, г. Белгород. Под ред. А.В. Полонского, 
C.В. Ушаковой, С.M. Нарожняя. Белгород, ИПЦ «ПОЛИТЕРРА»: 195-203. URL: https://journ.bsu.edu.ru/ files/discourse2019.pdf (дата обращения: 1.09.2021).

10. Lewicki R. 2017. Zagadnienia lingwistyki przekładu. Lublin, Wydawnictwo Uniwersytetu Marii Curie-Skłodowskiej, $362 \mathrm{s.}$

11. Lisowska-Magdziarz M. 2019. Znaki na uwięzi: Od semiologii do semantyki mediów. Kraków, Księgarnia Akademicka, 457 s. DOI: https://doi.org/10.12797/9788381381178

12. Loewe I. 2018. Od mediosfery do mediologii. IN: Wsółczesne media. Media multimodalne. T. 1: Zagadnienia ogólne i teoretyczne. Multimodalność mediów drukowanych. Eds. I. Hofman, D. KępaFigura. Lublin, Wydawnictwo UMCS: 21-33.

13. Maćkiewicz J. 2016. Jak można badać przekazy multimodalne. Język Polski, 2 (96): 18-27.

14. Piekot T. 2006. Dyskurs polskich wiadomości prasowych. Kraków, Universitas. 335 p.

15. Pstyga A. 2021a. Multimodalność przekazu medialnego a przekład (na podstawie rosyjskich tekstów publicystycznych i ich thumaczeń na język polski). Przegląd Rusycystyczny, 2(174): 39-54. DOI: $10.31261 /$ pr.10302

16. Pstyga A. 2021b. Przekład w komunikowaniu medialnym - perspektywa aksjologiczna. Gdańsk - Sopot, Wydawnictwo Uniwersytet Gdański, 207 p.

17. Skowronek B. 2016. Z perspektywy odbiorcy. O nowym obszarze badań języka w mediach. Język Polski, 2(96): 11-17.

18. Stőckl H. 2015. Lingwistyka mediów. O statusie i metodach (wciąż) konstytuującej się dyscypliny badawczej, tłum. J. Jarosz, R. Opiłowski. In. Lingwistyka mediów. Eds. R. Opiłowski, J. Jarosz J, P. Staniewski. Wrocław - Dresden, ATUT Neisse Verlag: 23-44.

19. Żydek-Bednarczuk U. 2013. Dyskurs medialny. In. Style współczesnej polszczyzny. Przewodnik po stylistyce polskiej. Eds. E. Malinowska, J. Nocoń, U. Żydek-Bednarczuk. Kraków, Universitas: 179-197.

\section{References}

1. Dobrosklonskaya T.G. 2008. Medialingvistika: sistemnyy podkhod k izucheniyu yazyka SMI: sovremennaya angliyskaya mediarech' [Medialinguistics: a systematic approach to learning the language of the media: modern English media speech]. Moskva, Publ. Flinta, Nauka, 264 p.

2. Kazak M.Yu. 2014. Sovremennye mediateksty: problemy identifikatsii, delimitatsii, tipologii [Modern media texts: problems of identification, delimitation, typology]. Medialingvistika, 1(4). Available at: https://medialing.ru/sovremennye-mediateksty-problemy-identifikacii-delimitacii-tipologii/ (accessed: 1.09.2021).

3. Kozhemyakin E.A. 2010. Mass Communication and Media Discourse: Towards Methodology. Scientific bulletin of Belgorod State University. Humanities Sciences, 12(83): 13-21 (in Russian).

4. Kozhemyakin E.A. 2019. Media text in multimodal perspective: several methodological remarks. In: Diskursologiya i mediakritika sovremennykh sredstv massovoy informatsii [Discourse and media criticism of modern media]. Sbornik trudov mezhdunarodnoy nauchno-prakticheskoy konferentsii, 2-4 oktyabrya 2019, g. Belgorod [Proceedings of the International Research-to-Practice Conference, Belgorod, 2-4 October 2019]. Ed. A.V. Polonsky, S.V. Ushakova, S.M. Narozhnyaya. Belgorod, Publ. IPTs «POLITERRA»: 158-164 (in Russian). Available at: https://journ.bsu.edu.ru/ files/discourse2019.pdf (accessed: 1.09.2021).

5. Korochenskiy A.P. 2018a. Tendentsiya gibridizatsii mediatekstov kak eticheskiy vyzov zhurnalistike [The trend of hybridization of media texts as an ethical challenge to journalism]. In: Mediynyy tekst: sotsial'nye praktiki, tekhnologii, teorii [Media text: social practices, technologies, theories]. Ed. A.V. Polonskoy, M.Yu. Kazak. Belgorod, Publ. ID «Belgorod» NIU «BelGU»: 147-150.

6. Korochenskiy A.P. 2018b. Mediakritika kak diskurs [Media criticism as discourse]. In: Mediynyy tekst: sotsial'nye praktiki, tekhnologii, teorii [Media text: social practices, technologies, theories]. Ed. A.V. Polonskoy, M.Yu. Kazak. Belgorod, Publ. ID «Belgorod» NIU «BelGU»: 218-219.

7. Polonskiy A.V. 2015. Media and their textual reality. Scientific bulletin of Belgorod State University. Humanities Sciences, 18 (215): 17-24 (in Russian).

8. Polonskiy A.V. 2018. Mediynyy tekst i ego status v sovremennoy kul'ture [Media text and its status in contemporary culture]. In: Mediynyy tekst: sotsial'nye praktiki, tekhnologii, teorii [Media text: social practices, technologies, theories]. Ed. A.V. Polonskoy, M.Yu. Kazak. Belgorod, Publ. ID «Belgorod» NIU «BelGU»: 9-24. 
9. Pstyga A. 2019. Media text and translation. In: Diskursologiya i mediakritika sovremennykh sredstv massovoy informatsii [Discourse and media criticism of modern media]. Proceedings of the International Research-to-Practice Conference, Belgorod, 2-4 October 2019. Ed. A.V. Polonsky, S.V. Ushakova, S.M. Narozhnyaya. Belgorod, Publ. IPTs «POLITERRA»: 195-203.(in Russian). Available at: https://journ.bsu.edu.ru/files/discourse2019.pdf (accessed: 1.09.2021)

10. Lewicki R. 2017. Zagadnienia lingwistyki przekładu [Issues of translation linguistics]. Lublin, Publ. Wydawnictwo Uniwersytetu Marii Curie-Skłodowskiej, 362 p.

11. Lisowska-Magdziarz M. 2019. Znaki na uwięzi: Od semiologii do semantyki mediów [Tethered signs: From semiology to media semantics]. Kraków, Publ. Księgarnia Akademicka, 457 p. DOI: https://doi.org/10.12797/9788381381178

12. Loewe I. 2018. Od mediosfery do mediologii [From media sphere to mediology]. In: Wsółczesne media. Media multimodalne [Contemporary media. Multimodal media]. Vol. 1: Zagadnienia ogólne i teoretyczne. Multimodalność mediów drukowanych [General and theoretical issues. Multimodality of printed media]. Eds. I. Hofman, D. Kępa-Figura. Lublin, Publ. Wydawnictwo UMCS: 21-33.

13. Maćkiewicz J. 2016. How it is possible to analyze multimodal messages. Język Polski, 2(96): 18-27 (in Polish).

14. Piekot T. 2006. Dyskurs polskich wiadomości prasowych [Discourse of Polish press news]. Kraków, Publ. Universitas, 335 p.

15. Pstyga A. 2021a. Multimodalność przekazu medialnego a przekład (na podstawie rosyjskich tekstów publicystycznych i ich tłumaczeń na język polski) [Multimodality of the media message and translation (based on Russian journalistic texts and their translations into Polish)]. Przegląd Rusycystyczny, 2(174): 39-54 (in Polish). DOI: 10.31261/pr.10302

16. Pstyga A. 2021b. Przekład w komunikowaniu medialnym - perspektywa aksjologiczna [Translation in Media Communication: an Axiological Perspective]. Gdańsk - Sopot, Publ. Wydawnictwo Uniwersytet Gdański, 207 p. (in Polish).

17. Skowronek B. 2016. Z perspektywy odbiorcy. O nowym obszarze badań języka w mediach [From the perspective of the recipient. On the new area of language research in the media]. Język Polski, 2 (96): 11-17 (in Polish).

18. Stőckl H. 2015. Lingwistyka mediów. O statusie i metodach (wciąż) konstytuującej się dyscypliny badawczej, thum. J. Jarosz, R. Opiłowski [Media linguistics. On the Status and Methods of an (Still) Establishing Research Discipline, transl. J. Jarosz, R. Opiłowski]. In: Lingwistyka mediów. Eds. R. Opiłowski, J. Jarosz J, P. Staniewski. Wrocław - Dresden, Publ. ATUT Neisse Verlag: 23-44 (in Polish).

19. Żydek-Bednarczuk U. 2013. Dyskurs medialny [Media discourse]. In: Style współczesnej polszczyzny. Przewodnik po stylistyce polskiej [Styles of contemporary Polish. A guide to Polish stylistics]. Eds. E. Malinowska, J. Nocoń, U. Żydek-Bednarczuk. Kraków, Publ. Universitas: 179-197 (in Polish).

Конфликт интересов: о потенциальном конфликте интересов не сообщалось.

Conflict of interest: no potential conflict of interest related to this article was reported.

\section{ИНФОРМАЦИЯ ОБ АВТОРЕ}

Пстыга Алиция, профессор гуманитарных наук, заведующая кафедрой русского языка и переводоведения Института русистики и востоковедения Гданьского университета, г. Гданьск, Польша

\section{INFORMATION ABOUT THE AUTHOR}

Alicia Pstyga, Professor of Humanities, Head of the Department of Russian Language and Translation Studies, Institute of Russian Studies and Oriental Studies, University of Gdansk, Gdansk, Poland 